\title{
Correction to: Solid sulfonated silica acid catalyst for epoxidation of podocarpus falcatus seed oil
}

\author{
Werku Aweke Teso ${ }^{1}$ Y Yigezu Mekonnen Bayisa ${ }^{1}$ (i)
}

๑) Springer-Verlag GmbH Germany, part of Springer Nature 2022

\section{Correction to: Biomass Conversion and Biorefinery https://doi.org/10.1007/s13399-021-02082-9}

The PDF version of this originally published article was the uncorrected proof; it has now been replaced by the corrected version. In addition, the order that the authors appeared in the author list was incorrect.

The original article has been corrected.

Publisher's Note Springer Nature remains neutral with regard to jurisdictional claims in published maps and institutional affiliations.

The online version of the original article can be found at https:// doi.org/10.1007/s13399-021-02082-9

Yigezu Mekonnen Bayisa

yigezu338@gmail.com

1 School of Chemical Engineering, Jimma Institute

of Technology, Jimma University, Jimma, Oromia, Ethiopia 